\title{
SPECIAL ASPECTS OF USING A MENTORING APPROACH TO TRAINING PUBLIC RELATIONS SPECIALISTS
}

\author{
Andrii Kyrychok \\ National Technical University of Ukraine “Igor Sikorsky Kyiv Polytechnic Institute”, Kyiv, Ukraine \\ akyrychok@ukr.net
}

This article presents the peculiarities of using mentoring approach to training public relations (PR) specialists. It includes a historiographical overview of the best practices related to the specifics of using mentoring in education. Based on the literature review, it proves that the use of a mentoring approach to training PR specialists has certain peculiarities and advantages. This paper provides the results of the study in the form of an online survey. Participants were practitioners and teachers working in the PR field. They had to answer questions related to the methodology of PR professional training at universities. Based on the data obtained, the main issues of mentoring assistance in preparing PR specialists have been discussed. The key methodological aspect of using mentoring assistance in PR training is using a pedagogical model "show-tell-do". This article covers general recommendations on integrating the mentoring approach into the process of PR specialist training at the university.

Keywords: public relations; education; mentoring; professional competencies; training model.

\section{Introduction}

Obtaining education in public relation (PR) training is currently rather popular with young people. On the one hand, there is a considerable demand for the specialists in this field on the labour market; on the other hand, there is a problem of contemporary education programmes being inadequate to current labour market requirements. The Ministry of Education of Ukraine issues some requirements to the professional training of students. Subsequently, the university designs the educational system so as to train specialists of the appropriate level, required by the government and the relevant field, using a competency-based approach to education. However, this algorithm is very often violated, which results in the training system being inadequate to the labour market requirements, as the problem of low competence of specialists in a certain field arises. Thus, it is of great importance to optimise PR specialist training programs as well as determine the approaches to developing the professional competencies in PR students. In our opinion, the mentoring approach to PR specialist training can be integrated into the education system. In this paper, we aim to prove the effectiveness of implementing the mentoring approach in training PR specialists at higher educational institutions.

\section{Mentoring as an international practice}

Mentoring has long been practised in international schools and universities and has proved to be an efficient educational method. Historically, mentoring as an instructional technique originated as early as in Ancient Greece; Socrates claimed that a teacher should teach a student through dialectics. Later, mentoring was developed in the works of scholars such as Jean-Jacques Rousseau, Konstantin Ushynskiy, etc. Mentoring was also a form of communist education. Over time, after the transition to market economy, mentoring as a teaching method gradually disappeared, but then it was applied in economics, business, and communications. Currently, most actively used are mentoring approaches developed in the USA. The mentoring approach was firstly used in the 1940s, but remained unsystematic for a long time In their classical form, mentoring programmes were not used until much later, namely, the early 2000s (Harold, 2008).

Many scholars worldwide investigated the problems of mentoring and the development prospects of this educational technique. Thus, mentoring assistance was studied in terms of agreement on mentoring quality assessment, as well as on the assessment criteria, between the mentor and the mentee (Godshalk \& Sosik, 2000). Mentoring was also viewed from the perspective of the mentor's and the mentee's compatibility with each other (Koberg, Boss \& Goodman, 1998). A number of studies were dedicated to the gender-based issues of mentoring. Thus, one study demonstrates that female mentors are more friendly and less demanding during the training process than their male colleagues (Sosik \& Godshalk, 2000).

Regarding the mentoring process itself, there is a popular belief among researchers that mentoring is similar to management and should be based on the views and values relevant to the modern times (Woodd, 1997). Many scholars, describing the mentoring process, point out official and non-official mentorship (Armstrong, Allinson \& Hayes, 2000). These two types of mentorship are substantially different; official mentorship is performed in line with an organisation's order, while non-official mentorship is defined by a person's development needs and lasts comparatively longer than the official one (Rosser, Egan 2003). 
Scholars have also considered other types of mentoring assistance, in particular, team (group) mentorship. The first study in this area was performed in 1990 and described the advantage of group mentorship over personal mentorship (Dansky, 1996). Other studies were also performed in this context that revealed the advantages of group mentorship in the military sphere (Knouse, 2000).

Following the advancement of the Internet, a kind of virtual mentorship, the so-called e-mentorship, appeared, which is an alternative communication method within the context of the traditional individual mentorship (Megginson, 2000).

Referring to the definition, a mentor, according to the etymological dictionary, is a curator, a teacher, a tutor, and a persistent supervisor for a student (Online Etymology Dictionary, 2016). The majority of the academic literature on mentorship describes the functions performed by mentors to the mentees' benefit. For instance, one study provides an example of the five key roles played by a mentor, namely, a trainer, a coordinator, a supporter, and an organiser (Clutterbuck, 1991). In another study, Zey (1982) lists the functions of a mentor, including those of a supervisor, a teacher, a person providing psychological support, an organiser, and a sponsor.

However, it should be noted that the majority of literature on mentorship results considers the benefits and results for the mentee. Thus, a number of studies refer to the issues related to the mentee's professional development, which manifests as an improvement in academic results (Sullivan, 2000; Summers-Ewing, 1994; and Joinson, 2001). Many studies prove the benefits of using mentoring approach for career and professional growth (Ragins, Cotton \& Miller, 2000; Scandura, Schreiesheim, 1994; Kram, 1986).

Despite the fact that most studies on mentoring are dedicated to the advantages of this approach for the mentee, there is a number of studies concerning the benefits gained by the mentor in working with the mentee (Hegstad, 1999). They include professional self-determination and related to the development of leadership and communication skills (Messmer, 2003).

Participation in mentorship is known to increase the mentee's chances of getting a fitting position in the organisation (O'Reilly, 2001). There is a large number of studies related to the mentoring process at all its stages and in individual domains of knowledge (Mullen, 1998; Verdejo, 2002; and Summers-Ewing, 1994), but insufficient studies are dedicated to the use of the mentoring approach to training public relations specialists.

However, in our research, we support the ideas of Megginson (2000) regarding the essence and content of this training system:

"Mentoring relates primarily to the identification and nurturing of potential for the whole person. It can be a long-term relationship, where the goals may change but are always set by the learner. The learner owns both the goals and the process. Feedback comes from within the mentee - the mentor helps them to develop insight and understanding through intrinsic observation, that is, becoming more aware of their own experiences." (p. 256)

The character of a mentor-student relationship can be different depending on the expected outcomes. In order to clarify these relationships it was suggested to classify them into the following mentoring models (Lord, Atkinson \& Mitchell, 2008): acquisition model (a mentor transmits skills and knowledge); sponsor model (a mentor helps establish certain business connections and acts as a manager); psychologist model (a mentor helps the student to solve their psychological problems); reflective model (a mentor acts as a constructive critic who assesses the student's work); competency model (a mentor emphases the practical component of training and development of professional competencies); development model (a mentor helps achieve personal and professional development through the reflection).

\section{The role of a mentor}

According to the research finding stated above, we can assume that mentoring is an indeterminate activity with specific but all-embracing ranging goals. The mentor's role is to encourage people to develop over an extended time period. A mentor should be adaptive and creative to apply skills, knowledge and experience to foster the educational progress. A mentor is supposed to develop in students research skills, text writing skills, anti-crisis management and strategic planning skills, advertising and PR projects handling skills, media planning and advertising/PR campaigns planning skills, analytical and communication skills, business negotiations skills, moral and ethical skills, customer communications skills, and public speaking skills.

Having reviewed the studies on mentoring we have defined the main peculiarities of a mentor comparing to a teacher which include developing educational activities according to the individual needs and learning style, focusing on interpersonal skills, assisting in furthering person's career. 
Mentoring assistance implies the cooperation between a mentor and a mentee, a student who should adopt the practices of a more experienced senior companion. In this case, a practitioner, a teacher, or a postgraduate student can act as a mentor. The mentoring approach has the following fundamental characteristics: longevity of the relationship between a mentor and a mentee; face-to-face discussion of work results throughout the training process; emphasis on the mentee's goals and aspirations, building on their capacities and skills; a mentor, having a mastery of interpersonal communication skills and communication process management.

A mentor can perform different roles throughout the training process; e.g., engage in role-playing with a student, depending on the type of assigned task, or urge a student to generate certain ideas. It is up to the mentor to choose an activity at a particular moment.

The mentoring approach brings a great number of benefits both to the student and to the mentee, as well as to the mentee's future employer, which will get a trained professional with certain qualifications, who will be psychologically prepared to perform any tasks.

Consequently, a mentor, as an expert, is expected to have certain skills required to share the experience with a mentee: be a professional having a vast array of theoretical knowledge and the ability to apply this knowledge in practice; maintain a contact with a mentee and create conditions for the mentee's rapid progress; select the activities, taking into account student's capabilities; be dedicated to continuous selfdevelopment and a search for new training and development forms.

An important aspect of the mentoring approach is the mentor's capability to set clear tasks for the students. One of the important techniques in mentoring is the "show-tell-do" model (Harold, 2008). It has the following stages: explaining the assignment to a student step by step, breaking it into parts if it is too large; ensuring that a student has understood the assignment; showing the way to perform a specific assignment, commenting on possible actions; checking whether a student has understood everything; supervising performance of the assignment and ask for the comments. If a mentor has doubts about the quality of performance of a particular assignment, there is a possibility to review a certain stage of the work in more details.

The mentoring assistance process can be subdivided into three stages (Messmer, 2003):

- Preparatory stage: implies preliminary acquaintance of the mentor with student(s). The primary task lies in establishing regular contact between the mentor and the student so that the process of knowledge transfer and reflection goes smoothly.

- Organisation and activity stage. This is the main stage to obtain practical training or perform selfstudy to develop necessary professional competencies. Its main purpose is to develop the skills and qualities required for future professional activity.

- Diagnostic stage. It is aimed at determining the level of development of professional competencies and creating certain recommendations for the student.

\section{Survey}

To find out whether using a mentorship to training PR specialists is appropriate, and which mentoring model would be the most efficient, we suggested Ukrainian teachers and practitioners fill in the questionnaire created for this research.

As the study targeted PR specialists, who are currently a rather numerous group, it was decided to use the sampling method. However, taking into account the specifics of the study, we did not aim to form a statistically significant sample. Nevertheless, the number of respondents surveyed in the course of statistic analysis may be sufficient to make firm statistical conclusions.

An Internet survey was performed by e-mailing questionnaires to potential respondents and via Vkontakte and Facebook social networks, by posting a link to the online survey web page (Online survey of Ukrainian educational practitioners).

\section{Results and discussion}

Since this article concerns the special aspects of using a mentorship to training public relations specialists, only the questions related to this issue are selected here from the large list of questions asked in the survey.

A total of 100 persons took part in the survey, among them $60 \%$ women and $40 \%$ men. The first three survey questions were of a general nature, concerning the gender, profession, and job title of the respondents, and were asked to determine the respondents' competence and to obtain statistical data on the age, occupation, and job titles of the respondents. 
The greatest amount of respondents specified PR as their occupational field (31\%), followed by advertising (27\%), marketing (23\%), education and science (18\%), journalism (12\%), and exhibition activities $(11 \%)$. The "other" option was also available (8\%).

The absolute majority of respondents $(83.1 \%)$ indicated that they consider mentorship in training advertising and PR specialists rather effective.

In the question regarding, the most efficient mentoring model, the respondents' answers distributed as follows: competency model (43\%), study model (18\%), development model (12\%), psychologist model (12\%), reflective model (8\%), sponsor model (7\%). As we can observe, the majority of respondents believe that mentoring assistance should be based on the competency model, which envisages the development of professional skills by gaining practical experience.

It is obvious that efficient mentorship requires a lot of changes in Ukrainian educational policy and is rather hard to implement in a full range. Unfortunately, it is impossible to replace teaching with mentoring at a university. Therefore, we suggest using mentoring assistance in combination with practical training in the PR education. We believe that using the mentoring approach is only appropriate in the last years of the Bachelor's or Master's programme. Since mentorship implies a transfer of practical skills and knowledge, students should have a good basic training in the speciality and related subjects.

Mentoring could give students practical knowledge and skills, develop their professional competencies needed for a future career faster and more efficiently than taking traditional university courses. In this case, combining mentoring approach with practical training, a mentor should ensure that students immerse themselves in the working atmosphere as deeply as possible. Gaining knowledge about the widest possible range of issues related to the functioning of the advertising and PR company or department will have a good educational effect on students. A mentoring approach in PR is aimed first of all at developing in students the abilities to work in a team, to create a high-quality information product, and to shape public opinion in the right way.

The key objective of mentoring is to design and realise the educational path for student's future career. Along with a mentor, a student gains the experience of goal setting to be able to manage one's own educational activity. At the PR Department, the National Technical University of Ukraine "Igor Sikorsky Kyiv Polytechnic Institute" the following forms of the mentor-student-cooperation have been developed and implemented: designing individual educational projects; reflective meetings with students out of classes; creating a professional portfolio.

The most efficient method of implementing mentoring approach is creating "student's resource map". This "map" includes the description of all resources, activities, hobbies etc which evoke interest or motivation in students and foster their self-realisation. In this regard, a mentor suggests reading scientific resources as well as attending additional courses, professional events and other activities. Our instructors have developed such "maps" with students and now they are implementing it. The experiment is going on now and we are expecting the outcomes at the end of an academic year. Next, we are planning to have a discussion of all carried events during the year and to discuss the efficacy of the suggested educational approach.

Together with a mentor, students draw up working schedule for a particular period of time. During their work, participants gain the necessary knowledge and develop particular skills, which is recorded by a mentor. At the end of practical training sessions, both a mentor and a student should write their reports. The student's report describes working process and the final practical results. The mentor's report should include an assessment of the personal qualities and skills of the person who underwent practical training, as well as a description work performance during the course.

\section{Conclusions}

The mentoring approach has proved to be rather efficient due to the fact that a student is able to gain the necessary knowledge and skills from a professional in a certain field. The use of this method in training PR specialists will have a considerable impact, since the mentoring approach, aimed at the development of the necessary professional competencies, will help future professionals adapt to their workplace as soon as possible, become part of a team, and be of benefit both to themselves and to the organisation they work in. 
References:

Armstrong, S. J., Allinson, C. W., \& Hayes, J. (2002, December). Formal mentoring systems: An examination of the effects of mentor/protégé cognitive styles on the mentoring process. The Journal of Management Studies, 39(8), 1111-1135. https://doi.org/10.1111/1467-6486.00326

Clutterbuck, D. (1991). Everyone needs a mentor: Fostering talent at work. London: Institute of Personnel Management.

Godshalk, V. M. \& Sosik, J. J. (2000, September). Does mentor-protégé agreement on mentor leadership behavior influence the quality of a mentoring relationship? Group \& Organization Management, 25(3), 291-318. https://doi.org/10.1177/1059601100253005

Hegstad, C. D. (1999). Formal mentoring as a strategy for human resource development: A review of research. Human Resource Development Quarterly, 10(4), 383-390. https://doi.org/10.1002/hrdq.3920100408

Joinson, C. (2001). Employee, sculpt thyself...with a little help. HRMagazine, 46(5), 60-64.

Knouse, S. B. \& Webb, S. C. (2000). Unique types of mentoring for diverse groups in the military. Review of Business, (Summer 2000), 48-52.

Koberg, C. S., Boss, R. W., and Goodman, E. (1998). Factors and outcomes associated with mentoring among health-care professionals. Journal of Vocational Behavior, 53(1), 58-72. https://doi.org/10.1006/jvbe.1997.1607

Megginson, D. (2000). Current issues in mentoring. Career Development International, 5(4/5), 256-260. https://doi.org/10.1108/eum0000000005364

Lord, P., Atkinson, M. and Mitchell, H. (2008). Mentoring and Coaching for Professionals: a Study of the Research Evidence .

Messmer, M. (2003). Building an effective mentoring program. Strategic Finance, 17-18.

Mullen, E. J. (1998). Vocational and psychosocial mentoring functions: Identifying mentors who serve both. Human Resource Development Quarterly, 9(4), 319-331. https://doi.org/10.1002/hrdq.3920090403

Summers-Ewing, D. (1994). Mentoring: A vital ingredient for career success. Presented at the Annual Meeting of the American Psychological Association (102nd, Los Angeles, CA).

O'Reilly, D. (2001). The mentoring of employees: Is your organization taking advantage of this professional development tool? Ohio CPA Journal, 60, 51-54

Online survey of practitioners and teachers (2016). Available at http://anketolog.ru/s/133394/BZTLBLUk

Ragins, B. R., Cotton, J. L., \& Miller, J. S. (2000, December). Marginal mentoring: The effects of type of mentor, quality of relationship, and program design on work and career attitudes. Academy of Management Journal, 43(6), 1177-1194. https://doi.org/10.2307/1556344

Rosser, M. \& Egan, T. M. (2003). Types and functions of mentoring relationships: A review of the literature. 2003 Academy of Human Resource Development Conference Proceedings, 2, 928-935.

Scandura, T. A. \& Schriesheim, C. A. (1994, December) Leader-member exchange and supervisor career mentoring as complementary concepts in leadership research. Academy of Management Journal, 37(6), 1588-1602. https://doi.org/10.2307/256800

Sullivan, J. (2011). True enough. Columbia Journalism Review, 50(1), 34-39.

Sosik, J. J. \& Godshalk, V. M. (2000). The role of gender in mentoring: Implications for diversified and homogenous mentoring relationships. Journal of Vocational Behavior, 57(1), 102-122. https://doi.org/10.1006/jvbe.1999.1734

Sullivan, R. (2000). Entrepreneurial learning and mentoring. International Journal of Entrepreneurial Behavior \& Research, 6(3), 160-175. https://doi.org/10.1108/13552550010346587

Summers-Ewing, D. (1994). Mentoring: A vital ingredient for career success. Presented at the Annual Meeting of the American Psychological Association (102nd, Los Angeles, CA).

Verdejo, T. (2002). Mentoring: A model method. Nursing Management, 33(8), 15-16. https://doi.org/10.1097/00006247-200208000$\underline{00009}$

White, C., Vanc, A., \& Stafford, G. (2010). Internal communication, information satisfaction, and sense of community: The effect of personal influence. Journal of Public Relations Research, 22(1), 65-84. https://doi.org/10.1080/10627260903170985

Woodd, M. (1997). Mentoring in further and higher education: Learning from the literature. Education and Training, 39(8/9), 333343. https://doi.org/10.1108/00400919710192368

Zhu, J. (2011). A question of ethics. Communication World, 28(3), 48 